\title{
Use of Mass Spectrometry to Screen Glycan Early Markers in Hepatocellular Carcinoma
}

\author{
Raphaela Menezes de Oliveira ${ }^{1}$, Carlos Andre Ornelas Ricart ${ }^{1}$ \\ and Aline Maria Araujo Martins ${ }^{1,2 *}$ \\ ${ }^{1}$ Laboratory of Biochemistry and Protein Chemistry, Department of Cell Biology, Institute of Biological Sciences, \\ University of Brasilia, Brasilia, Brazil, ${ }^{2}$ University Hospital Walter Cantídeo, Surgery Department, \\ Federal University of Ceara, Fortaleza, Brazil
}

\section{OPEN ACCESS}

Edited by:

Sebastian Cerdan,

Consejo Superior de Investigaciones Cientificas (CSIC), Spain

Reviewed by:

M. Carmen Martinez-Bisbal, Biomedical Research Networking

Center in Bioengineering, Biomaterials and Nanomedicine, Spain

Paloma V. Ballesteros, Universidad Nacional de Educación a Distancia, Spain Santosh Kumar Bharti, Johns Hopkins University, United States

*Correspondence: Aline Maria Araujo Martins alinemartins@unb.br

Specialty section: This article was submitted to Cancer Imaging and Diagnosis, a section of the journal

Frontiers in Oncology

Received: 01 October 2017 Accepted: 21 December 2017

Published: 15 January 2018

Citation:

de Oliveira RM, Ornelas Ricart CA and Araujo Martins AM (2018) Use of

Mass Spectrometry

to Screen Glycan Early Markers in Hepatocellular Carcinoma.

Front. Oncol. 7:328.

doi: $10.3389 /$ fonc. 2017.00328
Association between altered glycosylation patterns and poor prognosis in cancer points glycans as potential specific tumor markers. Most proteins are glycosylated and functionally arranged on cell surface and extracellular matrix, mediating interactions and cellular signaling. Thereby, aberrant glycans may be considered a pathological phenotype at least as important as changes in protein expression for cancer and other complex diseases. As most serum glycoproteins have hepatic origin, liver disease phenotypes, such as hepatocellular carcinoma (HCC), may present altered glycan profile and display important modifications. One of the prominent obstacles in HCC is the diagnostic in advanced stages when patients have several liver dysfunctions, limiting treatment options and life expectancy. The characterization of glycomic profiles in pathological conditions by means of mass spectrometry (MS) may lead to the discovery of early diagnostic markers using non-invasive approaches. MS is a powerful analytical technique capable of elucidating many glycobiological issues and overcome limitations of the serological markers currently applied in clinical practice. Therefore, MS-based glycomics of tumor biomarkers is a promising tool to increase early detection and monitoring of disease.

\section{Keywords: glycans, hepatocellular carcinoma, mass spectrometry, glycomics, biomarkers, cancer}

\section{INTRODUCTION}

The definition of glycans includes any form of mono-, oligo-, or polysaccharides free or disposed in glycoconjugates, which can be divided into glycoproteins, glycolipids, and glycosaminoglycans (GAGs) $(1,2)$. Some of the first studies of glycans, such as specific tumor markers, notice that poor prognostic in different cancers, such as breast and colon carcinoma, were related to aberrant glycosylation in glycoproteins $(3,4)$.

The role of glycans in the progression of cancer was initially proposed with the emergence of monoclonal antibodies against oncofetal carbohydrate antigens present in many cancers $(5,6)$. Since then, glycans from both neoplastic and regular cells were recognized as mediators of many pathophysiological events in cancer progression (3, 4, 7-9). For instance, activation of oncogenes and loss of tumor suppressors cause glycosylation alterations in neoplastic cells $(7,10)$. In tumor environment, changes such as fucosylation, sialylation, and high-mannose structures, provide increased proliferative capability, enabling the tumor cells to control key events for malignancy development. The most aggressive set of these changes include modulation of cell adhesion systems 
and cell motility, resulting in a "Darwinian selection" which promotes metabolism imbalance, cell invasion, and subsequent metastasis $(6,9,11,12)$. The migrating tumor cells can interact with leukocytes, endothelial cells, and platelets of lymphatic or blood vasculature through a unique highly expressed or altered glycan, such as Lewis blood antigens and $\mathrm{N}$-acetyllactosamine, thus amplifying the metastatic spread (13-15).

According to estimation, glycosylation is present in more than $50 \%$ of human proteins $(16,17)$. These glycoproteins are synthesized in various glycoforms which differ in placement site and molecular glycan structure. Concerning glycoproteins, the initial attachment of carbohydrate determines two main conjugation forms: $\mathrm{N}$-glycosylation, when is linked to the amino group of asparagine, and O-glycosylation, when is linked to hydroxyl group of serine or threonine (18).

Most glycoproteins are functionally arranged on cell surface and extracellular matrix (ECM) favoring mediation of cell interactions and signaling $(6,9)$. However, a matrix with few glycans favors invasion and metastatic potential in a wide range of tumors $(9,14)$. In 2009, Gornik and collaborators concluded that environmental changes and pathological development results in alterations in carbohydrate profile, revealing diagnostic potential (19).

Since posttranslational modifications (PTM) are important regulators of molecular machinery, altered phenotype resulting from glycan biosynthesis in pathological conditions may be more responsive than those related to changes in protein expression. Moreover, glycan modification combined with protein expression profiling can optimize the monitoring of development and progression of malignancies.

In 2010, a publication of Lauc and collaborators suggested that glycosylation status could indicate different risk factors for diseases (20). In fact, some tumor biomarkers presently used in clinical practice are glycoproteins found in blood, such as CEA, CA19-9, and CA-125 for colon, pancreatic, and ovarian cancer, respectively $(21-24)$.

Several studies were conducted to clarify the molecular events that result in liver tumor phenotypes, especially those linked to the emergence of hepatocellular carcinoma (HCC) (25-31). The late detection through biochemical tests and/or image diagnosis, generally in advanced stages of the disease, makes the HCC, one of the most aggressive cancers in the world $(32,33)$. This scenario shows the need for detection and validation of new biomarkers, highlighting the importance of glycomics approach, in characterization and control of glycosylation to establish the overall molecular profile of the pathological development process.

\section{IMPORTANCE OF GLYCANS IN CANCER}

The initial perception of glycans selection expressed on tumor cells resulted from their capacity to bind to a variety of plant lectins (34). Despite the diversity of glycoforms, restricted sorts of glycan structures are related to progression and poor prognosis in cancer (12).

Most cell surface receptors are $N$-linked glycoproteins, such as transforming growth factor receptor beta, epidermal growth factor receptor (EGFR), and integrins (35). Many secreted signaling molecules, such as growth factors and hormones, interact with cells via glycan-lectin interaction, often forming galectins and siglecs complexes $(36,37)$, which increase receptor availability on the cell surface $(36,38)$. Endogenous lectins enable essential processes such as quality control of secreted proteins, cell interactions, adhesion, and motility; therefore, the interaction of $\mathrm{N}$-glycans in glycoproteins with these molecules is critical for cellular adaptation during cancer $(9,39)$.

Another aspect of glycosylation in cancer is the upregulation of terminal glycan structures, such as tetrasaccharide NeuNAc $\alpha 2,3 \mathrm{Gal} \beta 1,4(\mathrm{Fuc} \alpha 1,3)$ GlcNAc, also known as sialyl Lewis $^{\mathrm{x}}\left(\operatorname{sLe}^{\mathrm{x}}\right)(3,7)$. The sLe ${ }^{\mathrm{x}}$ structures are mainly detected in $\beta 1-6$ GlcNAc branches carrying $N$-acetyllactosamine, the preferred ligand for galectin-3 (40). Increase of branching $\beta 1,6 \mathrm{GlcNAc} N$-glycans is related to metastatic behavior of tumor by changes in growth factor receptors on the surface of tumor cells $(41,42)$. The sLe ${ }^{\mathrm{x}}$ antigen was associated with progressive metastatic behavior and consequent poor prognosis due to its function in neoplastic cells adhesion to endothelium $(12,15,43)$. The antigen present discretely in vascular glycoproteins is the main binder of selectins and through this interaction, are able to mediate the early steps of leukocyte adhesion to endothelium (3, $35,44)$. Furthermore, hematogenous spread is the usual route of migration in carcinomas; thus, tumor cells carrying $\mathrm{sLe}^{\mathrm{x}}$ in the bloodstream can be linked to vascular selectins and contribute to cancer progression $(15,43,45-47)$.

Presentation of $\mathrm{SLe}^{\mathrm{x}}$ antigen and truncated forms of O-glycans were widely observed changes in cell carcinomas $(34,47,48)$. This type of cancer, in particular, expresses modified glycans on mucins, enabling binding to a variety of receptors and the consequent modulation of the biological properties of tumor cells $(10,14)$. Many mucins, such as MUC1, MUC2, and MUC4, are associated with tumor progression $(24,49,50)$.

Mucins are glycoproteins of epithelial cells heavily O-glycosylated that may comprise up to $80 \%$ by weight of the molecule (6). Although O-glycosylation is the regular classical pathway, N-glycosylation of mucins can also occur, either in normal or modified conditions $(16,51,52)$. The common structural characteristic of mucins is a tandem domain rich in serine, threonine, and proline residues (24). The first step in $\mathrm{O}$-glycosylation is the linkage of $\mathrm{N}$-acetylgalactosamine to these amino acid residues, also termed Tn antigens $(12,53)$.

Impairment of the glycosylation process of mucins, or by dysregulation expression of the mucin gene or enzyme involved in the biosynthesis of O-glycan, produces a high frequency of shorter structures, such as Tn antigens, $\mathrm{T}$ antigens, and both sialylated forms $(50,54)$.

The high expression of early Tn chains terminated by sialylation, the sialyl-Tn, reduces cellular interactions and increases the metastatic potential $(18,55,56)$. In other words, such molecules confer ability to travel through the ECM and to detach from the primary tumor (14). The sialylation of $\mathrm{T}$ antigens found in carcinomas is a consequence of increased expression of sialyltransferases, enzymes responsible for transfer sialic acid to glycoforms (57).

Glycosaminoglycans is a family composed by linear polysaccharides, mostly sulfated, containing repeating disaccharide units 
and present mainly in cell surfaces and extracellular matrices (9, 58). Through interaction with proteins, GAGs regulate several physiological processes acting mainly as "co-receptor," facilitating the formation of receptor-ligand complexes and reducing the effective concentration of ligand required for receptor activation $(9,58)$. Moreover, they favor the hoarding of binders for upcoming mobilization and shield against degradation $(6,59)$. In the tumor microenvironment, such functions are destitute, enabling growth factors released by the tumor exert autocrine and paracrine effects on surrounding host cells, such as endothelial cells (9).

Altered microenvironment is known to be involved in all stages of malignant progression, from initial transformation to invasion and metastasis, and many pathologists have recognized that some tumors are heavily infiltrated by both innate and adaptive immune system cells, thereby promoting inflammatory conditions in non-neoplastic tissue $(32,60,61)$. The interaction between accessory cells, their mediators, neoplastic cells, and structural components of the ECM, such as glycans, regulate all aspects of tumorigenicity (60).

\section{IMPORTANCE OF GLYCOMICS APPROACH IN EARLY MARKERS DISCOVERY}

By analogy with genomics, transcriptomics, and proteomics, the glycomics refers to studies that seek to define and quantify glycans in a cell, tissue, or organism $(1,6)$.

The challenge of glycomics is enormous, whereas glycosylation of proteins and lipids correspond to one of the most abundant PTM and also more structurally diverse (1, 62-64). Glycans often affect the functionality of the carrier proteins, so the joint analysis of these molecules, defined as glycoproteomics, is essential to understanding the universal role of glycans (7). However, the characterization of glycans in serum glycoproteins still is a challenge owing to the variety of glycoforms $(10,62,65)$.

There are only about 20 biomarkers approved and used clinically by the Food and Drug Administration (FDA), of which just 5 are validated for application in diagnosis $(66,67)$. Many of these biomarkers do not have sufficient specificity and sensitivity, and this may be explained by the readout based only in protein levels $(12,67)$. Protein abundance may not correlate with the stage of the disease, may differ among individuals and float in other diseases, especially those with inflammatory origin $(12,68)$.

In glycomics and glycoproteomics approach, comparison of overall glycan profiles in tissues or body fluids of interest allows the recognition and utilization of a new category of tumor biomarkers $(1,62,69)$. An ideal tumor biomarker would allow a simple blood test that can aid in clinical decisions to evaluate the risk of developing a disease, to permit early diagnosis and to characterize the disease stage, as well to monitor disease progression and treatment efficacy $(10,12)$.

Through advances in physical and biological chemistry, the field of glycobiology acquired the tools necessary to elucidate the composition and structure of glycans associated with cells and proteins (65). The glycomics study of tumor biomarkers and drug targets became an attractive field of research and widely exploited, as the importance of glycosylation alterations emerged $(2,18)$.

\section{IMPORTANCE OF HCC GLYCANS EARLY MARKERS}

Hepatocellular carcinoma is the most important late complication of chronic degenerative processes of the liver, derived from a primary liver disease $(18,32,70-72)$. In 2012, about 14.1 million of new cancer cases were registered, including 5.6\% corresponded to liver tumors, which is highlighted as within the five most common types of cancer in men (73).

The risk factors of HCC occurrence are well defined in the literature nowadays and among them, cirrhosis plays a major important role, along with hepatitis $\mathrm{B}$ virus and hepatitis $\mathrm{C}$ virus infection $(32,72,74)$. Alcohol abuse and metabolic syndromes, such as diabetes, also contributes as relevant risk factors $(32,72)$.

In current clinical practice, biopsy and diagnostic imaging, recommended by Barcelona and Milan criteria are the most reliable methods for detection of liver diseases (10). However, liver biopsy is not a recommended procedure for patients with HCC because it could allow physical tumor metastasis and imaging investigation is not able to reveal tumors in primary stages. Thus, there is a great urgency to use non-invasive markers that can routinely assess the progression of HCC and other liver diseases $(10,23,32,62,75)$.

The prognosis of patients with HCC presents rate of only $18 \%$ survival at 5 years, partly attributed to the diagnosis in advanced stages of the disease (76). One of the last curative resources in advanced HCC is orthotopic transplantation of the organ, whose recurrence reaches $10-20 \%$ of receptors, despite the use of strict criteria in the selection of candidates (77). The conventional system of tumor-node-metastasis staging is flawed in precognition of tumor recurrence after surgery owing to remarkable heterogeneity among patients at the same stage of HCC (78). Molecular approaches to stratify HCC patients through biomarker integration can assist in patient survival prediction and improve their prognostic stratification (79).

Most serum glycoproteins are from hepatic origin, so it is inferred that liver diseases associated with abnormal glycosylation can display significant changes in glycoproteins $(10,18,69)$. Previous works demonstrated that different phenotypes such as liver fibrosis, cirrhosis, and HCC features may be unravel by such changes in serum glycoproteins $(71,80-84)$.

Increased alpha-fetoprotein (AFP) is usually resulting from liver disease and changes at its glycoform is a good indicator of disease progression $(85,86)$. Many physiological conditions may affect serum levels of AFP, restricting the specificity of the marker, and the low detection sensitivity often contributes to recognition of HCC already in advanced stages $(29,80)$. The establishment of biomarkers of early expression can mitigate these difficulties and assist in differential diagnosis of liver diseases (80). In 2006, the glycosylated fraction AFP-L3, was approved by the FDA as an additional marker in early detection of HCC, since the sole 
determination of AFP concentration was not able to reveal initial stages of disease (87).

Studies correlating glycosylation patterns with HCC measure either activity or regulation of specific glycosyltransferases. However, in most cases, it was not found correlation between regulation of those enzymes and structural changes at the cell surface glycans (18).

Altered mannose structures have been reported frequently in the literature in several cancers, including HCC (88-90). Studies comparing purified carbohydrate chains from HCC against liver tissue notice that chains with high-mannose levels were found exclusively on pathological conditions $(90,91)$. The abundance of these molecules may facilitate not only the proliferation, adhesion, and tumor metastasis but also interactions with specific endothelial cells, determining in which organ or tissue is most likely the secondary tumor site (88). This fact reinforces the role played by microenvironment in metastasis formation first postulate by "soil-seed theory" of Stephen Paget (92).

Heparan sulfate (HSPG) is a sort of GAG, commonly reported in proteoglycans, associated with tumor cell proliferation (9). In HCC, as well as pancreas, breast, and ovary cancers, tumor cells are able to regulate Hsulf- 1 gene and consequently modulate sulfation of cell surface HSPGs in such way that promotes increased ability to bind to growth factors and better activation of tyrosine kinases receptors (93).

Venetz and collaborators correlated $N$-glycan structures and cancer-specific antibody effectiveness, and reported that non-sialylated glycans have a negative impact on the establishment of disease (8). Chia and collaborators suggested that the elucidation of short O-glycans structures regulation would expand therapeutic perspective, since many attempts to use such molecules as biomarkers, antibody, and therapeutic vaccine have failed, due to low sensitivity and/or specificity (12). Liu and collaborators evaluating HCC patients who underwent hepatectomy established correlation between high expression of $\beta 1,6-N$-acetylglucosaminiltransferase V (Mgat5) and recurrence and poor survival after procedure, revealing potential as an unfavorable biomarker (26). Finally, several works, summarized in Table 1, have shown an association between aberrant glycosylation profile and HCC phenotype (25, 27, 29, 47, 80, 90, 93-105). Thus, the most important types of glycosylation are show in Figure 1.

The techniques for surveillance of HCC remains controversial. Although suggestions that biomarkers improve early detection, the usual serum molecular markers that are used, such as AFP, des- $\gamma$-carboxyprothrombin (DCP), and the L3 fraction of AFP (AFP-L3), are all more frequently associated with advanced stage disease and there is no evidence that leads to improved cure rates (32). The use of glycans as markers is a considerable alternative and also a challenge for the diagnosis of diseases, since biochemical environment alterations could impact in glycosylation machinery (69).

\section{MASS SPECTROMETRY (MS) AS A TOOL FOR GLYCOMICS ANALYSIS}

In recent years, challenges in glycomics have been unraveled by many innovative approaches and methods, accelerating the
TABLE 1 | Changes in glycosylation associated with hepatocellular carcinoma phenotype.

\begin{tabular}{|c|c|c|}
\hline Glycan modification & Proposed major function & Reference \\
\hline $\begin{array}{l}\text { Increased } \beta-1,6-\text { GlcNAc } \\
\text { branching on } N \text {-glycans }\end{array}$ & $\begin{array}{l}\text { Decreased cell adhesion to } \\
\text { fibronectin }\end{array}$ & $(110)$ \\
\hline $\begin{array}{l}\text { Increased sialylated GlcNAc } \\
\text { branching on } N \text {-glycans }\end{array}$ & $\begin{array}{l}\text { Decreased cell-cell interaction, } \\
\text { enhanced motility and } \\
\text { invasiveness }\end{array}$ & $(110)$ \\
\hline $\begin{array}{l}\text { Increased fucosylation of core } \\
\text { and outer-arm }\end{array}$ & $\begin{array}{l}\text { Decreased cell polarity and } \\
\text { altered adhesive properties }\end{array}$ & $(99-102)$ \\
\hline $\begin{array}{l}\text { Increased fucosylation and } \\
\text { sialylation of } \beta \text { chain on } \\
\text { haptoglobin }\end{array}$ & Altered adhesive properties & (83) \\
\hline $\begin{array}{l}\text { Increased expression of sLe } \\
\text { structures }\end{array}$ & $\begin{array}{l}\text { Enhanced tumor cell adhesion } \\
\text { during metastasis }\end{array}$ & $(25,47)$ \\
\hline $\begin{array}{l}\text { Increased expression of high- } \\
\text { mannose structures }\end{array}$ & $\begin{array}{l}\text { Enhanced proliferation, } \\
\text { adhesion, and metastasis }\end{array}$ & $(25,29,95)$ \\
\hline $\begin{array}{l}\text { Increased fucosylated, sialylated, } \\
\text { and complex } N \text {-glycans }\end{array}$ & $\begin{array}{l}\text { Increase activity of the } \\
\text { epidermal growth factor } \\
\text { receptor (EGF-R), decreased } \\
\text { cell-cell interaction, enhanced } \\
\text { motility and invasiveness }\end{array}$ & $\begin{array}{l}(27,103 \\
105-107)\end{array}$ \\
\hline $\begin{array}{l}\text { Increased of bi-sialylated } \\
\text { O-glycopeptide of hemopexin }\end{array}$ & Altered adhesive properties & $(107)$ \\
\hline $\begin{array}{l}\text { Increased expression of multiply } \\
\text { fucosylated Ley in haptoglobin }\end{array}$ & $\begin{array}{l}\text { Enhanced tumor cell adhesion } \\
\text { during metastasis }\end{array}$ & $(108)$ \\
\hline $\begin{array}{l}\text { Increased of core- } \alpha-1,6- \\
\text { fucosylated triantennary glycan }\end{array}$ & Enhanced cell migration & $(109)$ \\
\hline $\begin{array}{l}\text { Increased of } \alpha-1,3-f u c o s y l a t e d \\
\text { branching on triantennary glycan }\end{array}$ & $\begin{array}{l}\text { Decreased cell polarity and } \\
\text { altered adhesive properties }\end{array}$ & $(104)$ \\
\hline
\end{tabular}

acquisition of glycobiological data. While investigation methods and protocols for glycomic and glycoproteomic studies progressed, glycobiological challenges have been reduced and the effects of specific glycans gradually determined. Among these methods, MS showed to be an essential tool for the expansion of glycosylation biological meaning (105). Figure 2 demonstrates a protocol frequently used for glycomic analysis in MS biomarkers research.

Complex mixtures of glycans, derived from clinical samples for example, are often separated by chromatography or capillary electrophoresis and detected by fluorescence or MS. Fluorescence detection requires fluorescently tagged glycans and results in partial structural data from chromatographic or electrophoretic retention times, while MS can also be applied on native oligosaccharides and may provide detailed structural data through increasement of resolution power, such as Fourier transform ion cyclotron resonance or techniques such as hydrogen deuterium exchange mass spectrometry and ion mobility separation (IMS) $(1,28,102,106)$. MS can clarify glycan structural characteristics that are difficult to elucidate without deglycosylation and, if combined with glycopeptide analysis, provide a thorough knowledge of the micro and macro heterogeneity of protein glycosylation (107).

A promising non-invasive strategy to discover early biomarkers of cancer is characterizing glycomic patterns in pathological serum or plasma and MS, in particular, is an enabled technology for this analysis $(105,108)$. The constant advancement rendered the $\mathrm{N}$ - and $\mathrm{O}$-glycomic characterization possible nonetheless 


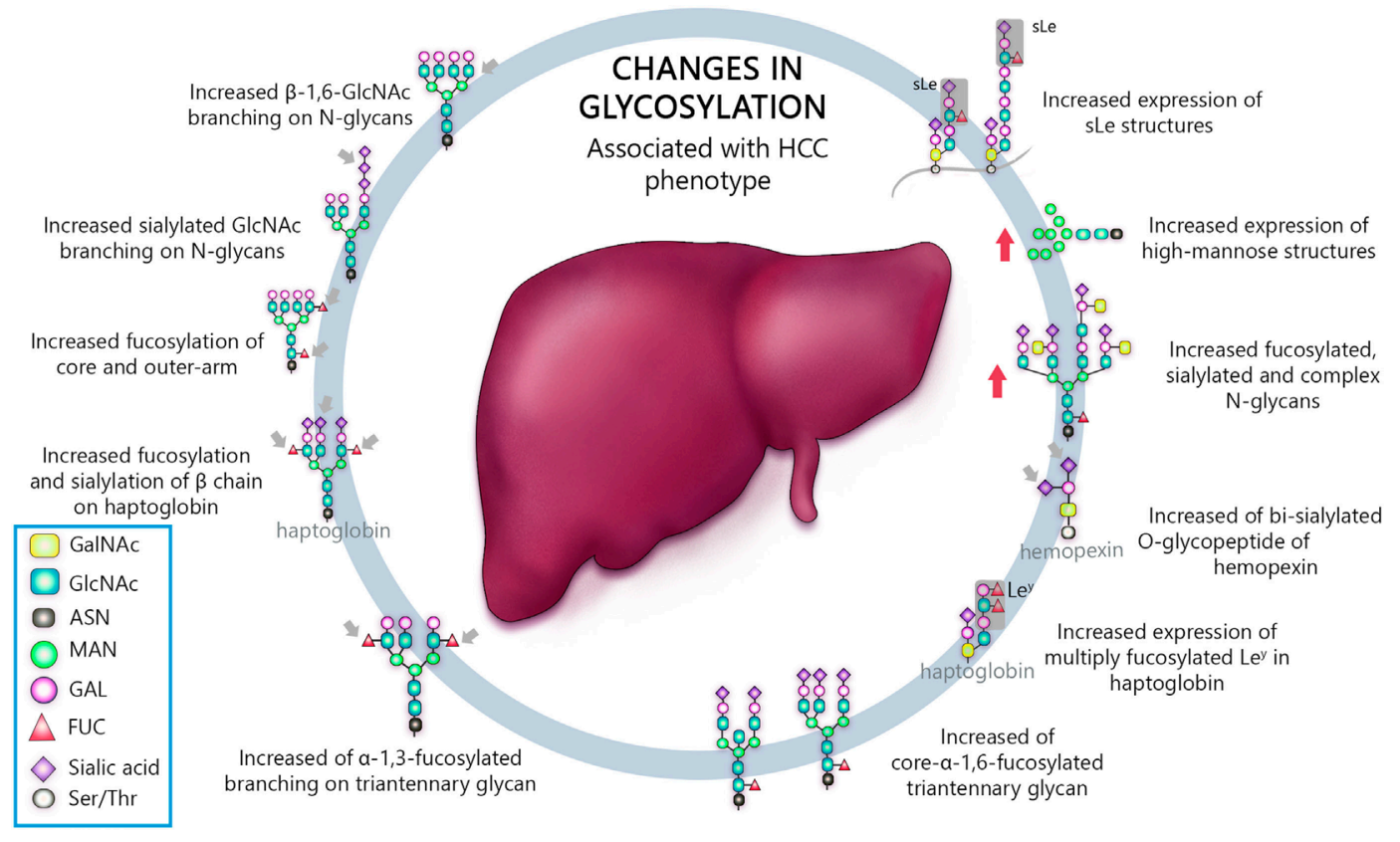

FIGURE 1 | Schematic representation of the most important glycan alterations associated with hepatocellular carcinoma (HCC) phenotype.

there is no consensus on the ideal method of investigation and each one presents both advantages and disadvantages. Specifically, for concomitant examination of both $\mathrm{N}$ - and $\mathrm{O}$-glycan structures, porous graphitized carbon separation with electrospray ionization (ESI) followed by MS/MS has been highlighted as a successful workflow (1).

Matrix-assisted laser desorption/ionization mass spectrometry (MALDI-MS) is an effective technique for $\mathrm{N}$-glycomic analysis of clinical samples and has been widely applied to identify $N$-glycans in $\operatorname{HCC}(27,109)$. Its relatively tolerance to salt and other contaminants permit simple sample preparation after $N$-glycan enrichment. Kim and collaborators evaluated the performance of a quantitative MALDI targeting glycomics approach, in the analysis of $\mathrm{N}$-glycans, in both, purified AFP from normal cord blood (control condition) and from HCC cell line-Huh7 cells-(increase of core-fucosylation). It was demonstrated that the results are promising in clinical and bioengineering fields (110). In 2009, Lattová and collaborators examined serum of animal models with HCC-inducted through MALDI-MS, identifying forty different $\mathrm{N}$-glycans, in which some structures appeared to have highest frequency in HCC samples (29). Kamiyama and collaborators, also applying MALDI-MS analysis, reporting two $\mathrm{N}$-glycan structures, G2890 and G3560, which were presented as potential biomarkers of malignancy in HCC (27).

Another pragmatic technique for investigation of glycans and glycoproteins in body fluids is the ESI-MS, therefore, potentially cancer biomarkers can be assigned by its use and in HCC field, this is already widely exploited $(105,111)$. In 2013, Zhang and collaborators through LC-ESI-MS/MS analysis reported that $\beta$ haptoglobin chain sialylated and fucosylated glycoforms may be associated with early hepatocarcinogenesis therefore may be useful as differential monitoring markers for patients with cirrhosis and HCC (80). Another research group also demonstrated with LC-ESI-MS that fucosylated haptoglobin structures are upregulated in HCC if compared to cirrhotic samples (112). Tsai and collaborators also through LC-ESI-MS approach, and comparing serum samples from HCC and cirrhotic patients, inferred $11 \mathrm{~N}$-glycan structures with different regulation between the 2 biological conditions and therefore possible biomarkers candidates (105). As notice, the specificity of these MS methods, MALDI-MS and ESI-MS, is frequently related to the raw intensities of glycan ions in the two contrasting scenarios, non-pathological versus pathological samples (28).

During recent years, to include information regarding the number and abundance of distinct isomers and conformers, separation methods, such as liquid chromatography (LC) and IMS, has been frequently associated to MS. ESI is especially well suited to LC-MS approach and according to $\mathrm{Hu}$ and Mechref, the system formed possibly presents higher sensitivity than MALDI-MS and LC-MALDI-MS in detecting permethylated $\mathrm{N}$-glycans from serum (111). Isailovic et al., analyzing $N$-glycans to describe diseases states, combined IMS-MS and a three-dimensional IMS-IMS-MS technique that aims to describe variations in structure based on creation of new conformations instead of ion fragments (28). Statistical analyses of these IMS distributions proposed that deviations in isomer distributions may denote some disease states, showing that IMS is suitable to complement MS analysis.

Mass spectrometry-based glycomic and glycoproteomic investigation require, besides the appropriate equipment, a fair amount of expertise. Glycoproteomic approaches usually consist of numerous steps but, in recent years, alternative strategies for 


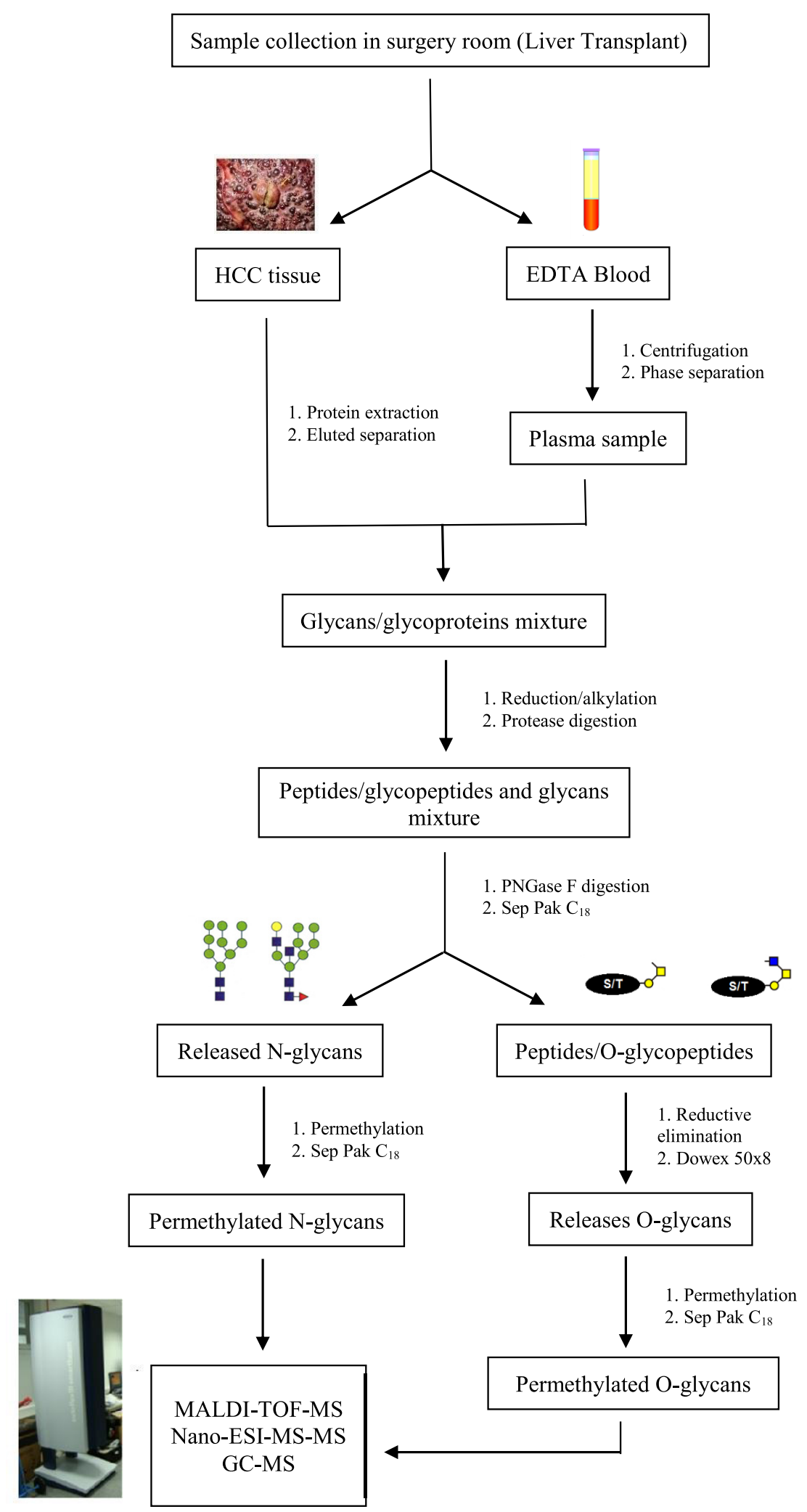

FIGURE 2 | Schematic representation of the preparation process for glycomics analysis in mass spectrometry biomarkers research. Protocols for glycoprotein analysis depend on the amount of sample. Since biomarkers research often use tissue or serum/plasma samples, the strategy adopted does not require presence of SDS for protein denaturation but is only applicable if more than $50 \mathrm{mg}$ of protein is available. If you are not interested studding O-glycosylation in the moment, you can storage the peptides/O-glycopeptides and proceed directly to permethylation of $\mathrm{N}$-glycans. 
production of site-specific structural insights of $\mathrm{N}$ - and O-glycans are being optimized $(113,114)$. Whole glycopeptide analysis using a blend of distinct MS fragmentation techniques or collision energies that fragment peptides or glycans, awakens the possibility of discovering new complex diseases markers; therefore, it may be of great value for the study of glycan early markers in cancer $(1,113,114)$.

An additional novel and promising MS approach for detection of in situ glycan alteration of specific proteins is mass spectrometry imaging (MSI) (115). This method produces for each ionization point a spectrum that presents structural data that may be correlated with the analyte spatial distribution in targeted tissue. MSI has been improved for glycomic studies and can generate $\mathrm{N}$-glycosylation signatures of a variety of tissues (116), including formalin-fixed paraffin-embedded tissues (117). When applied on HCC tissues, MALDI imaging was able to spatially identify $\mathrm{N}$-glycan compositions and distingue global profiling from nonpathological tissues (118).

Recently, real-time ex vivo MS for tumor detection has been performed as an alternative for histological diagnose. In general, the standard equipment and sample preparation, essential to produce MS data, is very elaborate for clinical use. Since rapid evaporative ionization mass spectrometry was apply to a surgical instrument (iKnife) in order to recognize lipid profiling of regular and cancerous human breast tissue, other adaptations in operating room have also simplified the physical structure and requirement for specialists, supporting the clinical purpose $(119,120)$.

Although MS is the most suitable technique for analysis of complex glycan samples, glycomics is currently insidious due to structural characterization and automation, to become a regular choice of investigation in clinical area. However, analysis of other biomolecules (such as lipids and metabolites) have already been implemented as cutting-edge MS application, not only in clinical practice but also in surgical center, such as MasSpec Pen technology (120-123).

\section{REFERENCES}

1. Mereiter S, Balmaña M, Gomes J, Magalhães A, Reis CA. Glycomic approaches for the discovery of targets in gastrointestinal cancer. Front Oncol (2016) 6:55. doi:10.3389/fonc.2016.00055

2. Lauc G, Pezer M, Rudan I, Campbell H. Mechanisms of disease: the human N-glycome. Biochim Biophys Acta (2016) 1860:1574-82. doi:10.1016/j. bbagen.2015.10.016

3. Kannagi R. Carbohydrate-mediated cell adhesion involved in hematogenous metastasis of cancer. Glycoconj J (1997) 14:577-84. doi:10.1023/ A:1018532409041

4. Kim YJ, Varki A. Perspectives on the significance of altered glycosylation of glycoproteins in cancer. Glycoconj J (1997) 14:569-76. doi:10.1023/ A: 1018580324971

5. Feizi T. Demonstration by monoclonal antibodies that carbohydrate structures of glycoproteins and glycolipids are onco-developmental antigens. Nature (1985) 314:53-7. doi:10.1038/314053a0

6. Varki A, Cummings RD, Esko JD, Freeze HH, Stanley P, Bertozzi CR, et al. Essentials of Glycobiology. 2nd ed. New York: Cold Spring Harbor Laboratory Press (2009).

7. Miura Y, Endo T. Glycomics and glycoproteomics focused on aging and agerelated diseases - glycans as a potential biomarker for physiological alterations. Biochim Biophys Acta (2016) 1860:1608-14. doi:10.1016/j.bbagen.2016.01.013

\section{CONCLUSION}

Glycans are involved in numerous essential biological functions that are altered in tumor and tumor microenvironment, suggesting that such components are intimately associated with the neoplastic condition. Due to its biopathological characteristics and lack of an early biomarker, HCC display very limited curative options. HCC patients usually present late diagnosis detection, when the cancer is already in advanced stages. The absence of specificity in the laboratory diagnosis, inconclusive image analysis, and invasive characteristic of liver biopsy procedure contribute to the poor prognosis of these patients. A clear view on initial clinical stages of the disease is a determining factor for choice of curative treatment, as well as for its success. Non-invasive markers not only measure the risk of developing HCC and other liver diseases in its early stages, as it can routinely evaluate its progression. Current advances in glycobiology field could help vanquish the several issues remain to be understood, particularly in complex diseases such as HCC. MS proved to be an enabling tool for noninvasive strategies in future validation of potential glycobiomarkers and translation in clinical venue. In this scenario, the study of glycans and its characteristics represents a hopeful implement for better knowledge of cancer biological properties, especially in HCC. The emerging concept of translational medicine has drawn a lot of attention in the last decade and one of the premises is the implementation of high-performance techniques in clinical settings to demystify the usage of analytical tools in downstream services that might have high impact on patients' health.

\section{AUTHOR CONTRIBUTIONS}

RO has contributed to the drafting, writing, and revision of the manuscript. CR has contributed to writing and revision of the manuscript. AM has contributed to the conception, writing, and revision of the manuscript. All authors approved the review final form.

8. Venetz D, Hess C, Lin C, Aebi M, Neri D. Glycosylation profiles determine extravasation and disease-targeting properties of armed antibodies. Proc Natl Acad Sci U S A (2015) 112:2000-5. doi:10.1073/pnas.1416694112

9. Fuster MM, Esko JD. The sweet and sour of cancer: glycans as novel therapeutic targets. Nat Rev Cancer (2005) 5:526-42. doi:10.1038/nrc1649

10. Adamczyk B, Tharmalingam T, Rudd PM. Glycans as cancer biomarkers. Biochim Biophys Acta (2012) 1820:1347-53. doi:10.1016/j.bbagen.2011.12.001

11. Kazuno S, Furukawa J-I, Shinohara Y, Murayama K, Fujime M, Ueno T, et al. Glycosylation status of serum immunoglobulin $\mathrm{G}$ in patients with prostate diseases. Cancer Med (2016) 5:1137-46. doi:10.1002/cam4.662

12. Chia J, Goh G, Bard F. Short O-GalNAc glycans: regulation and role in tumor development and clinical perspectives. Biochim Biophys Acta (2016) 1860:1623-39. doi:10.1016/j.bbagen.2016.03.008

13. Johnson JL, Jones MB, Ryan SO, Cobb BA. The regulatory power of glycans and their binding partners in immunity. Trends Immunol (2013) 34:290-8. doi:10.1016/j.it.2013.01.006

14. Bapu D, Runions J, Kadhim M, Brooks SA. N-acetylgalactosamine glycans function in cancer cell adhesion to endothelial cells: a role for truncated O-glycans in metastatic mechanisms. Cancer Lett (2016) 375:367-74. doi:10.1016/j.canlet.2016.03.019

15. Kannagi R, Izawa M, Koike T, Miyazaki K, Kimura N. Carbohydrate-mediated cell adhesion in cancer metastasis and angiogenesis. Cancer Sci (2004) 95:377-84. doi:10.1111/j.1349-7006.2004.tb03219.x 
16. Kudelka MR, Ju T, Heimburg-Molinaro J, Cummings RD. Simple sugars to complex disease - mucin-type O-glycans in cancer. Adv Cancer Res (2015) 126:53-135. doi:10.1016/bs.acr.2014.11.002

17. Apweiler R, Hermjakob H, Sharon N. On the frequency of protein glycosylation, as deduced from analysis of the SWISS-PROT database. Biochim Biophys Acta (1999) 1473:4-8. doi:10.1016/S0304-4165(99)00165-8

18. Christiansen MN, Chik J, Lee L, Anugraham M, Abrahams JL, Packer NH. Cell surface protein glycosylation in cancer. Proteomics (2014) 14:525-46. doi:10.1002/pmic.201300387

19. Gornik O, Wagner J, Pučić M, Knežević A, Redžić I, Lauc G. Stability of N-glycan profiles in human plasma. Glycobiology (2009) 19:1547-53. doi:10.1093/glycob/cwp134

20. Lauc G, Essafi A, Huffman JE, Hayward C, Knežević A, Kattla JJ, et al. Genomics meets glycomics - the first GWAS study of human N-glycome identifies HNF $1 \alpha$ as a master regulator of plasma protein fucosylation. PLoS Genet (2010) 6:e1001256. doi:10.1371/journal.pgen.1001256

21. Terzi H, Kale E, Kale A, Turkay U, Chong GO, Lee YS. New method: are tumor markers in vaginal-washing fluid significant in the diagnosis of primary ovarian carcinoma? Eur J Gynaecol Oncol (2015) 36:560-3.

22. Kim J-H, Jun K-H, Jung H, Park I-S, Chin H-M. Prognostic value of preoperative serum levels of five tumor markers (carcinoembryonic antigen, CA19-9, alpha-fetoprotein, CA72-4, and CA125) in gastric cancer. Hepatogastroenterology (2014) 61:863-9.

23. Zhang D, Yu M, Xu T, Xiong B. Predictive value of serum CEA, CA19-9 and CA125 in diagnosis of colorectal liver metastasis in Chinese population. Hepatogastroenterology (2013) 60:1297-301. doi:10.5754/hge121125

24. Hollingsworth MA, Swanson BJ. Mucins in cancer: protection and control of the cell surface. Nat Rev Cancer (2004) 4:45-60. doi:10.1038/nrc1251

25. Amin A, Bashir A, Zaki N, McCarthy D, Ahmed S, Lotfy M. Insights into glycan biosynthesis in chemically-induced hepatocellular carcinoma in rats: a glycomic analysis. World J Gastroenterol (2015) 21:6167-79. doi:10.3748/wjg. v21.i20.6167

26. Liu H, Wu Q, Liu Y, Liu W, Zhang W, Pan D, et al. Prognostic significance of beta1,6-N-acetylglucosaminyltransferase $\mathrm{V}$ expression in patients with hepatocellular carcinoma. Jpn J Clin Oncol (2015) 45:844-53. doi:10.1093/ jjco/hyv080

27. Kamiyama T, Yokoo H, Furukawa JI, Kurogochi M, Togashi T, Miura N, et al. Identification of novel serum biomarkers of hepatocellular carcinoma using glycomic analysis. Hepatology (2013) 57:2314-25. doi:10.1002/hep.26262

28. Isailovic D, Kurulugama RT, Plasencia MD, Stokes ST, Kyselova Z, Goldman R, et al. Profiling of human serum glycans associated with liver cancer and cirrhosis by IMS-MS. J Proteome Res (2008) 7:1109-17. doi:10.1021/pr700702r

29. Lattová E, McKenzie EJ, Gruwel MLH, Spicer V, Goldman R, Perreault H. Mass spectrometric study of N-glycans from serum of woodchucks with liver cancer. Rapid Commun Mass Spectrom (2009) 23:2983-95. doi:10.1002/ rcm.4202

30. Whittaker S, Marais R, Zhu AX. The role of signaling pathways in the development and treatment of hepatocellular carcinoma. Oncogene (2010) 29:4989-5005. doi:10.1038/onc.2010.236

31. Villanueva A, Newell P, Chiang DY, Friedman SL, Llovet JM. Genomics and signaling pathways in hepatocellular carcinoma. Semin Liver Dis (2007) 27:55-76. doi:10.1055/s-2006-960171

32. Llovet JM, Zucman-Rossi J, Pikarsky E, Sangro B, Schwartz M, Sherman M, et al. Hepatocellular carcinoma. Nat Rev Dis Prim (2016) 2:16018. doi:10.1038/ nrdp. 2016.18

33. Okuda K. Hepatocellular carcinoma. J Hepatol (2000) 32:225-37. doi:10.1016/ S0168-8278(00)80428-6

34. Raedler A, Schreiber S. Analysis of differentiation and transformation of cells by lectins. CritRevClinLabSci(1988)26:153-93.doi:10.3109/10408368809106861

35. Kiermaier E, Moussion C, Veldkamp CT, Gerardy-Schahn R, de Vries I, Williams LG, et al. Polysialylation controls dendritic cell trafficking by regulating chemokine recognition. Science (2016) 351:186-90. doi:10.1126/ science.aad0512

36. Crocker PR, Paulson JC, Varki A. Siglecs and their roles in the immune system. Nat Rev Immunol (2007) 7:255-66. doi:10.1038/nri2056

37. Lau KS, Dennis JW. N-Glycans in cancer progression. Glycobiology (2008) 18:750-60. doi:10.1093/glycob/cwn071

38. Lau KS, Partridge EA, Grigorian A, Silvescu CI, Reinhold VN, Demetriou M, et al. Complex N-Glycan number and degree of branching cooperate to regulate cell proliferation and differentiation. Cell (2007) 129:123-34. doi:10.1016/j.cell.2007.01.049

39. Dennis JW, Lau KS, Demetriou M, Nabi IR. Adaptive regulation at the cell surface by N-glycosylation. Traffic (2009) 10:1569-78. doi:10.1111/j. 1600-0854.2009.00981.x

40. Fukuda M, Spooncer E, Oates JE, Dell A, Klock JC. Structure of sialylated fucosyl lactosaminoglycan isolated from human granulocytes. J Biol Chem (1984) 259:10925-35.

41. Partridge EA, Le Roy C, Di Guglielmo GM, Pawling J, Cheung P, Granovsky M, et al. Regulation of cytokine receptors by golgi $\mathrm{N}$-glycan processing and endocytosis. Science (2004) 306:120-4. doi:10.1126/science.1102109

42. Dennis JW, Laferté S, Waghorne C, Breitman ML, Kerbel RS. Beta 1-6 branching of Asn-linked oligosaccharides is directly associated with metastasis. Science (1987) 236:582-5. doi:10.1126/science.2953071

43. Borsig L, Wong R, Feramisco J, Nadeau DR, Varki NM, Varki A. Heparin and cancer revisited: mechanistic connections involving platelets, P-selectin, carcinoma mucins, and tumor metastasis. Proc Natl Acad Sci (2001) 98:3352-7. doi:10.1073/pnas.061615598

44. Läubli H, Borsig L. Selectins promote tumor metastasis. Semin Cancer Biol (2010) 20:169-77. doi:10.1016/j.semcancer.2010.04.005

45. Julien S, Ivetic A, Grigoriadis A, QiZe D, Burford B, Sproviero D, et al. Selectin ligand sialyl-Lewis $\mathrm{x}$ antigen drives metastasis of hormone-dependent breast cancers. Cancer Res (2011) 71:7683-93. doi:10.1158/0008-5472.CAN-11-1139

46. Borsig L, Wong R, Hynes RO, Varki NM, Varki A. Synergistic effects of L- and $\mathrm{P}$-selectin in facilitating tumor metastasis can involve non-mucin ligands and implicate leukocytes as enhancers of metastasis. Proc Natl Acad Sci U S A (2002) 99:2193-8. doi:10.1073/pnas.261704098

47. Takada A, Ohmori K, Yoneda T, Tsuyuoka K, Hasegawa A, Kiso M, et al. Contribution of carbohydrate antigens sialyl Lewis A and sialyl Lewis X to adhesion of human cancer cells to vascular endothelium. Cancer Res (1993) 53:354-61.

48. Brockhausen I. Mucin-type O-glycans in human colon and breast cancer: glycodynamics and functions. EMBO Rep (2006) 7:599-604. doi:10.1038/ sj.embor.7400705

49. Byrd JC, Bresalier RS. Mucins and mucin binding proteins in colorectal cancer. Cancer Metastasis Rev (2004) 23:77-99. doi:10.1023/A:1025815113599

50. Taylor-Papadimitriou J, Burchell J, Miles D, Dalziel M. MUC1 and cancer. BiochimBiophysActa(1999)1455:301-13.doi:10.1016/S0925-4439(99)00055-1

51. Kinlough CL, Poland PA, Bruns JB, Harkleroad KL, Hughey RP. MUC1 membrane trafficking is modulated by multiple interactions. J Biol Chem (2004) 279:53071-7. doi:10.1074/jbc.M409360200

52. He J, Baum LG. Galectin interactions with extracellular matrix and effects on cellular function. Methods Enzymol (2006) 417:247-56. doi:10.1016/ S0076-6879(06)17017-2

53. Freire T, Osinaga E. Immunological and biomedical relevance of the $\mathrm{Tn}$ antigen. Immunología (2003) 22:27-38.

54. Brockhausen I, Yang J, Dickinson N, Ogata S, Itzkowitz SH. Enzymatic basis for sialyl-Tn expression in human colon cancer cells. Glycoconj J (1998) 15:595-603. doi:10.1023/A:1006967910803

55. Julien S, Adriaenssens E, Ottenberg K, Furlan A, Courtand G, VercoutterEdouart A, et al. X LB. ST6GalNAc I expression in MDA-MB-231 breast cancer cells greatly modifies their O-glycosylation pattern and enhances their tumourigenicity. Glycobiology (2006) 16:54-64. doi:10.1093/glycob/cwj033

56. Leivonen M, Nordling S, Lundin J, von Boguslawski K, Haglund C. STn and prognosisinbreastcancer.Oncology (2001)61:299-305.doi:10.1159/000055337

57. Hanisch F-G. O-glycosylation of the mucin type. Biol Chem (2001) 382:143-9. doi:10.1515/BC.2001.022

58. Shao C, Shi X, Phillips JJ, Zaia J. Mass spectral profiling of glycosaminoglycans from histological tissue surfaces. Anal Chem (2013) 85:10984-91. doi:10.1021/ ac402517s

59. Esko JD, Lindahl U. Molecular diversity of heparan sulfate. J Clin Invest (2001) 108:169-73. doi:10.1172/JCI13530

60. Palucka AK, Coussens LM. The basis of oncoimmunology. Cell (2016) 164:1233-47. doi:10.1016/j.cell.2016.01.049

61. Hanahan D, Weinberg RA. Hallmarks of cancer: the next generation. Cell (2011) 144:646-74. doi:10.1016/j.cell.2011.02.013

62. Song T, Aldredge D, Lebrilla CB. A method for in-depth structural annotation of human serum glycans that yields biological variations. Anal Chem (2015) 87:7754-62. doi:10.1021/acs.analchem.5b01340 
63. Dell A, Morris HR. Glycoprotein structure determination by mass spectrometry. Science (2001) 291:2351-6. doi:10.1126/science.1058890

64. Hart GW, Copeland RJ. Glycomics hits the big time. Cell (2010) 143:672-6. doi:10.1016/j.cell.2010.11.008

65. Hudak JE, Bertozzi CR. Glycotherapy: new advances inspire a reemergence of glycans in medicine. Chem Biol (2014) 21:16-37. doi:10.1016/ j.chembiol.2013.09.010

66. National Cancer Institute. Tumor markers. Natl Cancer Inst (2015).

67. Kulasingam V, Diamandis EP. Strategies for discovering novel cancer biomarkers through utilization of emerging technologies. Nat Clin Pract Oncol (2008) 5:588-99. doi:10.1038/ncponc1187

68. Marella DS. Prognostic and predictive markers in early detection of different types of cancers for selected organ sites. IOSR J Pharm Biol Sci (2013) 8:25-42. doi:10.9790/3008-0842542

69. Malaguarnera G, Bertino G, Vacante M, Malaguarnera M. Hepatocellular carcinoma markers in the omics era: the glycomic analysis. Hepatobiliary Surg Nutr (2014) 3(6):407-9. doi:10.3978/j.issn.2304-3881.2014.07.04

70. Ma Y-C, Yang J-Y, Yan L-N. Relevant markers of cancer stem cells indicate a poor prognosis in hepatocellular carcinoma patients: a metaanalysis. Eur J Gastroenterol Hepatol (2013) 25:1007-16. doi:10.1097/MEG. 0b013e32836019d8

71. Hernandez-Gea V, Turon F, Berzigotti A, Villanueva A. Management of small hepatocellular carcinoma in cirrhosis: focus on portal hypertension. World J Gastroenterol (2013) 19:1193-9. doi:10.3748/wjg.v19.i8.1193

72. European Association for the Study of the Liver, European Organisation for Research and Treatment of Cancer. EASL-EORTC clinical practice guidelines: management of hepatocellular carcinoma. J Hepatol (2012) 56:908-43. doi:10.1016/j.jhep.2011.12.001

73. Ferlay J, Soerjomataram I, Dikshit R, Eser S, Mathers C, Rebelo M, et al. Cancer incidence and mortality worldwide: sources, methods and major patterns in GLOBOCAN 2012. Int J Cancer (2015) 136:E359-86. doi:10.1002/ ijc. 29210

74. Bruix J, Hessheimer AJ, Forner A, Boix L, Vilana R, Llovet JM. New aspects of diagnosis and therapy of hepatocellular carcinoma. Oncogene (2006) 25:3848-56. doi:10.1038/sj.onc. 1209548

75. Dancey JE, Chen HX. Strategies for optimizing combinations of molecularly targeted anticancer agents. Nat Rev Drug Discov (2006) 5:649-59. doi:10.1038/nrd2089

76. Padhya KT, Marrero JA, Singal AG. Recent advances in the treatment of hepatocellular carcinoma. Curr Opin Gastroenterol (2013) 29:285-92. doi:10.1097/MOG.0b013e32835ff1cf

77. Vivarelli M, Risaliti A. Liver transplantation for hepatocellular carcinoma on cirrhosis: strategies to avoid tumor recurrence. World J Gastroenterol (2011) 17:4741-6. doi:10.3748/wjg.v17.i43.4741

78. Dragani TA. Risk of HCC: genetic heterogeneity and complex genetics. J Hepatol (2010) 52:252-7. doi:10.1016/j.jhep.2009.11.015

79. Kaseb AO, Morris JS, Hassan MM, Siddiqui AM, Lin E, Xiao L, et al. Clinical and prognostic implications of plasma insulin-like growth factor-1 and vascular endothelial growth factor in patients with hepatocellular carcinoma. J Clin Oncol (2011) 29:3892-9. doi:10.1200/JCO.2011.36.0636

80. Zhang S, Jiang K, Sun C, Lu H, Liu Y. Quantitative analysis of site-specific $\mathrm{N}$-glycans on sera haptoglobin $\beta$ chain in liver diseases. Acta Biochim Biophys Sin (Shanghai) (2013) 45:1021-9. doi:10.1093/abbs/gmt110

81. Blomme B, Van Steenkiste C, Callewaert N, Van Vlierberghe H. Alteration of protein glycosylation in liver diseases. J Hepatol (2009) 50:592-603. doi:10.1016/j.jhep.2008.12.010

82. Callewaert N, Van Vlierberghe H, Van Hecke A, Laroy W, Delanghe J, Contreras R. Noninvasive diagnosis of liver cirrhosis using DNA sequencer-based total serum protein glycomics. Nat Med (2004) 10:429-34. doi:10.1038/nm1006

83. Marrero JA, Romano PR, Nikolaeva O, Steel L, Mehta A, Fimmel CJ, et al. GP73, a resident Golgi glycoprotein, is a novel serum marker for hepatocellular carcinoma. J Hepatol (2005) 43:1007-12. doi:10.1016/j.jhep. 2005.05.028

84. Meany DL, Chan DW. Aberrant glycosylation associated with enzymes as cancer biomarkers. Clin Proteomics (2011) 8:7. doi:10.1186/1559-0275-8-7

85. Dai Z, Zhou J, Qiu SJ, Liu YK, Fan J. Lectin-based glycoproteomics to explore and analyze hepatocellular carcinoma-related glycoprotein markers. Electrophoresis (2009) 30:2957-66. doi:10.1002/elps.200900064
86. Taketa K. A tetrazolium method for peroxidase staining: application to the antibody-affinity blotting of $\alpha$-fetoprotein separated by lectin affinity electrophoresis. Electrophoresis (1987) 8:409-14. doi:10.1002/elps.1150080908

87. Taniguchi $\mathrm{N}$. Toward cancer biomarker discovery using the glycomics approach. Proteomics (2008) 8(16):3205-8. doi:10.1002/pmic.200890056

88. de Leoz MLA, Young LJT, An HJ, Kronewitter SR, Kim J, Miyamoto S, et al. High-mannose glycans are elevated during breast cancer progression. Mol Cell Proteomics (2011) 10:M110.002717. doi:10.1074/mcp.M110.002717

89. Lattová E, Varma S, Bezabeh T, Petruš L, Perreault H. Mass spectrometric profiling of $\mathrm{N}$-linked oligosaccharides and uncommon glycoform in mouse serum with head and neck tumor. J Am Soc Mass Spectrom (2008) 19:671-85. doi:10.1016/j.jasms.2008.01.016

90. Yamashita K, Totani K, Iwaki Y, Takamisawa I, Tateishi N, Higashi T, et al. Comparative study of the sugar chains of gamma-glutamyltranspeptidases purified from human carcinoma and from human liver. J Biochem (1989) 105:728-35. doi:10.1093/oxfordjournals.jbchem.a122736

91. Wang N, Kang X-N, Liu Y-K, Guo K, Cui J-F, Sun R-X, et al. Membrane protein glycan profiling of hepatocellular carcinoma cell with different metastastic potential by lectin microarray. Prog Biochem Biophys (2009) 36:1348-55. doi:10.3724/SP.J.1206.2009.00120

92. Ribatti D, Mangialardi G, Vacca A. Stephen Paget and the "seed and soil" theory of metastatic dissemination. Clin Exp Med (2006) 6:145-9. doi:10.1007/ s10238-006-0117-4

93. Lai J, Chien J, Staub J, Avula R, Greene EL, Matthews TA, et al. Loss of HSulf-1 up-regulates heparin-binding growth factor signaling in cancer. J Biol Chem (2003) 278:23107-17. doi:10.1074/jbc.M302203200

94. Block TM, Comunale MA, Lowman M, Steel LF, Romano PR, Fimmel C, et al. Use of targeted glycoproteomics to identify serum glycoproteins that correlate with liver cancer in woodchucks and humans. Proc Natl Acad Sci U S A (2005) 102:779-84. doi:10.1073/pnas.0408928102

95. Comunale MA, Lowman M, Long RE, Krakover J, Philip R, Seeholzer S, et al. Proteomic analysis of serum associated fucosylated glycoproteins in the development of primary hepatocellular carcinoma. J Proteome Res (2006) 5:308-15. doi: $10.1021 / \mathrm{pr} 050328 \mathrm{x}$

96. Goldman R, Ressom HW, Varghese RS, Goldman L, Bascug G, Loffredo CA, et al. Detection of hepatocellular carcinoma using glycomic analysis. Clin Cancer Res (2009) 15:1808-13. doi:10.1158/1078-0432.CCR-07-5261

97. Comunale MA, Wang M, Hafner J, Krakover J, Rodemich L, Kopenhaver B, et al. Identification and development of fucosylated glycoproteins as biomarkers of primary hepatocellular carcinoma. J Proteome Res (2009) 8:595-602. doi:10.1021/pr800752c

98. Mehta A, Norton P, Liang H, Comunale MA, Wang M, Rodemich-Betesh L, et al. Increased levels of tetra-antennary N-linked glycan but not core fucosylation are associated with hepatocellular carcinoma tissue. Cancer Epidemiol Biomarkers Prev (2012) 21:925-33. doi:10.1158/1055-9965. EPI-11-1183

99. Liu X-E, Desmyter L, Gao C-F, Laroy W, Dewaele S, Vanhooren V, et al. $\mathrm{N}$-glycomic changes in hepatocellular carcinoma patients with liver cirrhosis induced by hepatitis B virus. Hepatology (2007) 46:1426-35. doi:10.1002/ hep. 21855

100. Xiang T, Yang G, Liu X, Zhou Y, Fu Z, Lu F, et al. Alteration of N-glycan expression profile and glycan pattern of glycoproteins in human hepatoma cells after HCV infection. Biochim Biophys Acta (2017) 1861:1036-45. doi:10.1016/j.bbagen.2017.02.014

101. Tanabe K, Kitagawa K, Kojima N, Iijima S. Multifucosylated alpha-1-acid glycoprotein as a novel marker for hepatocellular carcinoma. J Proteome Res (2016) 15:2935-44. doi:10.1021/acs.jproteome.5b01145

102. Darebna P, Novak P, Kucera R, Topolcan O, Sanda M, Goldman R, et al. Changes in the expression of $\mathrm{N}$ - and O-glycopeptides in patients with colorectal cancer and hepatocellular carcinoma quantified by full-MS scan FT-ICR and multiple reaction monitoring. J Proteomics (2017) 153:44-52. doi:10.1016/j.jprot.2016.09.004

103. Pompach P, Brnakova Z, Sanda M, Wu J, Edwards N, Goldman R. Site-specific glycoforms of haptoglobin in liver cirrhosis and hepatocellular carcinoma. Mol Cell Proteomics (2013) 12:1281-93. doi:10.1074/mcp.M112.023259

104. Nie H, Liu X, Zhang Y, Li T, Zhan C, Huo W, et al. Specific N-glycans of hepatocellular carcinoma cell surface and the abnormal increase of core- $\alpha-1$, 6-fucosylated triantennary glycan via $\mathrm{N}$-acetylglucosaminyltransferases-IVa regulation. Sci Rep (2015) 5:16007. doi:10.1038/srep16007 
105. Tsai T, Wang M, Di Poto C, Hu Y, Zhou S, Zhao Y, et al. LC-MS profiling of $\mathrm{N}$-glycans derived from human serum samples for biomarker discovery in hepatocellular carcinoma. J Proteome Res (2014) 13:4859-68. doi:10.1021/ pr500460k

106. Guttman M, Scian M, Lee KK. Tracking hydrogen/deuterium exchange at glycan sites in glycoproteins by mass spectrometry. Anal Chem (2011) 83:7492-9. doi:10.1021/ac201729v

107. Jensen PH, Karlsson NG, Kolarich D, Packer NH. Structural analysis of N- and O-glycans released from glycoproteins. Nat Protoc (2012) 7:1299-310. doi:10.1038/nprot.2012.063

108. Mechref Y, Hu Y, Garcia A, Hussein A. Identifying cancer biomarkers by mass spectrometry-based glycomics. Electrophoresis (2012) 33:1755-67. doi:10.1002/elps.201100715

109. Tang Z, Varghese RS, Bekesova S, Loffredo CA, Hamid MA, Kyselova Z, et al. Identification of $\mathrm{N}$-glycan serum markers associated with hepatocellular carcinoma from mass spectrometry data. J Proteome Res (2010) 9:104-12. doi:10.1021/pr900397n

110. Kim K-J, Kim Y-W, Hwang C-H, Park H-G, Yang Y-H, Koo M, et al. A MALDI-MS-based quantitative targeted glycomics (MALDI-QTaG) for total N-glycan analysis. Biotechnol Lett (2015) 37:2019-25. doi:10.1007/ s10529-015-1881-6

111. Hu Y, Mechref Y. Comparing MALDI-MS, RP-LC-MALDI-MS and RP-LCESI-MS glycomic profiles of permethylated N-glycans derived from model glycoproteins and human blood serum. Electrophoresis (2012) 33:1768-77. doi:10.1002/elps.201100703

112. Zhang Y, Zhu J, Yin H, Marrero J, Zhang XX, Lubman DM. ESI-LC-MS method for haptoglobin fucosylation analysis in hepatocellular carcinoma and liver cirrhosis. J Proteome Res (2015) 14:5388-95. doi:10.1021/acs. jproteome.5b00792

113. An HJ, Froehlich JW, Lebrilla CB. Determination of glycosylation sites and site-specific heterogeneity in glycoproteins. Curr Opin Chem Biol (2009) 13:421-6. doi:10.1016/j.cbpa.2009.07.022

114. Hinneburg H, Stavenhagen K, Schweiger-Hufnagel U, Pengelley S, Jabs W, Seeberger $\mathrm{PH}$, et al. The art of destruction: optimizing collision energies in quadrupole-time of flight (Q-TOF) instruments for glycopeptide-based glycoproteomics. J Am Soc Mass Spectrom (2016) 27:507-19. doi:10.1007/ s13361-015-1308-6

115. Everest-Dass AV, Briggs MT, Kaur G, Oehler MK, Hoffmann P, Packer NH. $\mathrm{N}$-glycan MALDI imaging mass spectrometry on formalin-fixed paraffin-embedded tissue enables the delineation of ovarian cancer tissues. Mol Cell Proteomics (2016) 15:3003-16. doi:10.1074/mcp.M116.059816
116. Powers TW, Jones EE, Betesh LR, Romano PR, Gao P, Copland JA, et al. Matrix assisted laser desorption ionization imaging mass spectrometry workflow for spatial profiling analysis of $\mathrm{N}$-linked glycan expression in tissues. Anal Chem (2013) 85:9799-806. doi:10.1021/ac402108x

117. Powers TW, Neely BA, Shao Y, Tang H, Troyer DA, Mehta AS, et al. MALDI imaging mass spectrometry profiling of $\mathrm{N}$-glycans in formalin-fixed paraffin embedded clinical tissue blocks and tissue microarrays. PLoS One (2014) 9:e106255. doi:10.1371/journal.pone.0106255

118. Powers TW, Holst S, Wuhrer M, Mehta AS, Drake RR. Two-dimensional N-glycan distribution mapping of hepatocellular carcinoma tissues by MALDI-imaging mass spectrometry. Biomolecules (2015) 5:2554-72. doi:10.3390/biom5042554

119. Balog J, Sasi-Szabo L, Kinross J, Lewis MR, Muirhead LJ, Veselkov K, et al. Intraoperative tissue identification using rapid evaporative ionization mass spectrometry. Sci Transl Med (2013) 5:ra93-194. doi:10.1126/scitranslmed.3005623

120. St John ER, Balog J, McKenzie JS, Rossi M, Covington A, Muirhead L, et al. Rapid evaporative ionisation mass spectrometry of electrosurgical vapours for the identification of breast pathology: towards an intelligent knife for breast cancer surgery. Breast Cancer Res (2017) 19:59. doi:10.1186/ s13058-017-0845-2

121. Zhang J, Rector J, Lin JQ, Young JH, Sans M, Katta N, et al. Nondestructive tissue analysis for ex vivo and in vivo cancer diagnosis using a handheld mass spectrometry system. Sci Transl Med (2017) 9:eaan3968. doi:10.1126/ scitranslmed.aan3968

122. Eberlin LS, Norton I, Dill AL, Golby AJ, Ligon KL, Santagata S, et al. Classifying human brain tumors by lipid imaging with mass spectrometry. Cancer Res (2012) 72:645-54. doi:10.1158/0008-5472.CAN-11-2465

123. Zhang J, Yu W, Suliburk J, Eberlin LS. Will ambient ionization mass spectrometry become an integral technology in the operating room of the future? Clin Chem (2016) 62:1172-4. doi:10.1373/clinchem.2016.258723

Conflict of Interest Statement: The authors declare that the research was conducted in the absence of any commercial or financial relationships that could be construed as a potential conflict of interest.

Copyright (C) 2018 de Oliveira, Ornelas Ricart and Araujo Martins. This is an open-access article distributed under the terms of the Creative Commons Attribution License (CC BY). The use, distribution or reproduction in other forums is permitted, provided the original author(s) or licensor are credited and that the original publication in this journal is cited, in accordance with accepted academic practice. No use, distribution or reproduction is permitted which does not comply with these terms. 